\title{
Colelitíase no paciente pediátrico portador de doença falciforme
}

\author{
Cholelithiasis in children with sickle cell disease
}

Ana Paula S. Gumiero ${ }^{1}$, Maria Ângela B. Brandão², Elizete Aparecida L. C. Pinto ${ }^{3}$, Ana Claudia dos Anjos ${ }^{4}$

\section{RESUMO}

Objetivo: Considerando a alta freqüência da colelitíase no paciente pediátrico com doença falciforme e a controvérsia na literatura sobre a abordagem da condição, o presente texto objetiva revisar a literatura disponível.

Fontes de dados: Revisão dos estudos sobre colelitíase no paciente falciforme, publicados no período entre 1980 e 2007, em língua inglesa e portuguesa, envolvendo pacientes na faixa etária de zero a 18 anos e utilizando os bancos de dados Medline e Lilacs.

Síntese dos dados: A colelitíase é a complicação digestiva mais comum no paciente falciforme e sua incidência aumenta com a faixa etária. Os mecanismos fisiopatológicos são conhecidos, assim como os métodos diagnósticos. A conduta terapêutica consensual na colelitíase sintomática é a colecistectomia, preferencialmente por via laparoscópica. Nos casos assintomáticos, a maioria dos autores recomenda a conduta cirúrgica, para evitar complicações, confusão no diagnóstico diferencial de dor abdominal futura e menor risco cirúrgico. Contudo, não existe consenso na literatura, havendo base para a adoção de conduta expectante.

Conclusões: A doença falciforme tem grandes variações em sua apresentação clinica, história natural e gravidade da hemólise. Algumas populações podem apresentar menor frequiência de colelitíase e menor número de pacientes sintomáticos, possivelmente em razão de variações de haplótipos, fatores ambientais e diferentes manejos clínicos. Ainda não existem dados suficientes na literatura ou estudos randomizados e controlados que possibilitem definir o momento ideal para a colecistectomia no paciente falciforme com litíase assintomática. Dessa maneira, dependendo de características individuais e da população, podem ser aceitos o seguimento clínico ou a indicação precoce de colecistectomia.

Palavras-chave: anemia falciforme; colelitíase; colecistectomia; criança.

\section{ABSTRACT}

Objective: Given the high frequency of cholelithiasis in children with sickle cell disease and the controversies about its management, the aim of this study was to critically review the literature about this issue.

Data sources: Published studies in English and Portuguese from 1980 to 2007 about cholelithiasis and sickle cell anemia in children were retrieved from Medline and Lilacs databases.

Data synthesis: Cholelithiasis is the most common digestive complication of sickle cell disease patients and its frequency increases with age. Physiopathology of gallstones and diagnostic methods are well established. Cholecystectomy is the recommended therapy for symptomatic cholelithiasis, preferentially by laparoscopic approach. In asymptomatic patients, most studies favors the surgical management of the disease in order to avoid complications and to reduce difficulties with the differential diagnosis of future abdominal pain. However, the clinical management of this condition is also possible and there is no consensus in the literature regarding the best approach.

Conclusions: Sickle cell disease presents great variations in clinical presentation, natural history and severity of hemolysis. Some populations may present lower frequency of cholelithiasis and its symptoms. Variability in the frequency of this complication may be attributed to genetic variation in haplotipes, environmental factors, clinical course and management of the sickle cell disease. Scientific evidence regarding the best time to indicate cholecystectomy in asymptomatic patient is not available. Therefore, decision regarding the need of clinical or surgical approach of the cholelithiasis depends on individual and population factors.

Key-words: anemia, sickle cell; cholelithiasis; cholecystectomy; child.

Endereço para correspondência

Ana Paula dos S. Gumiero

Rua Boa Morte, 194, apto. 53 - Centro

CEP 13480-180, Limeira/SP

E-mail: aninha75@uol.com.br

Recebido em: 26/7/2007

Aprovado em: 14/9/2007 


\section{Introdução}

A anemia falciforme é uma condição hereditária de caráter recessivo, na qual a síntese da hemoglobina é alterada. É caracterizada clinicamente por hemólise crônica e recorrente, anemia crônica, suscetibilidade a infecções, crises agudas de dor decorrentes de microinfartos e disfunção de diversos órgãos. Trata-se de uma das doenças genéticas mais freqüentes, de distribuição universal, com maior predomínio na região da África Equatorial, onde atinge até $3 \%$ da população ${ }^{(1,2)}$. No Brasil, estima-se que acometa até $0,3 \%$ da população negra, podendo ser mais significativa em decorrência do alto grau de miscigenação racial ${ }^{(1)}$. A doença falciforme é extremamente variável em sua expressão clínica e evolução, sendo possível uma mudança em sua história natural como resultado de um melhor manejo.

Estima-se que até $50 \%$ dos adultos jovens falciformes apresentem complicaç̃ôes digestórias relacionadas à presença de barro biliar (bile espessa) e colelitíase. Essa freqüência passa a ser mais significativa a partir dos cinco anos de idade, aumentando progressivamente na adolescência e na idade adulta ${ }^{(3-8)}$. Vários estudos mostram menor freqüência da litíase biliar em algumas populações de doentes falciformes, o que pode ser explicado por variabilidade dos haplótipos, miscigenação genética, atenuando ou agravando a expressão clínica da doença. Além disso, em alguns estudos, a casuística inclui populações mais jovens ${ }^{(9-12)}$. Outros fatores ambientais, como a alimentação, também podem estar envolvidos.

O objetivo desse estudo foi realizar revisão bibliográfica sobre colelitíase em crianças portadoras de doença falciforme. Foram incluídas as publicações referentes ao período entre janeiro de 1980 e fevereiro de 2007, utilizando os bancos de dados Medline e Lilacs, com os seguintes limites: artigos originais ou de revisão publicados em língua inglesa ou portuguesa, realizados em humanos com idades entre zero e 18 anos e com os descritores "anemia falciforme", "colelitíase" e "colecistectomia".

\section{Fisiopatologia da colelitíase no paciente falciforme}

A hemólise crônica característica da doença falciforme é o fator de risco mais importante para o desenvolvimento de litíase biliar. A formação de cálculos biliares pigmentados se dá pela destruição prematura dos eritrócitos falcizados, acúmulo de seus precursores e precipitação dos sais bilia- res (bilirrubinato de cálcio), além de hiperbilirrubinemia indireta crônica ${ }^{(3,4,13-16)}$. A hemólise é a principal causa de colelitíase em crianças e adolescentes ${ }^{(17)}$.

$\mathrm{O}$ aumento da concentração de bilirrubinato, acima da solubilidade normal, resulta em precipitação. As maiores concentrações de bilirrubina indireta ocorrem na anemia falciforme com os padrões eletroforéticos SS e S-Beta Talassemia - tais pacientes apresentam maior risco para desenvolver litíase biliar. Em contraponto, os pacientes com padrão SC têm menor incidência de colelitíase por apresentarem hemólise mais branda e menores níveis de bilirrubina indireta ${ }^{(7)}$. Os cálculos em geral são múltiplos e pigmentados, radiopacos e com sombra acústica posterior, facilmente identificáveis ao exame de ultra-som ${ }^{(3,13,15)}$.

A enzima uridina difosfoglucoronato glucoroniltransferase 1 A (UDP-UGT1A) participa do metabolismo da bilirrubina e mutações relacionadas a essa enzima vêm sendo associadas a níveis séricos elevados de bilirrubina e ao desenvolvimento de litíase biliar sintomática ${ }^{(18-22)}$.

\section{Diagnóstico}

A colelitíase no paciente falciforme pode ser diagnosticada na fase assintomática e assim permanecer por longos períodos de tempo.

O diagnóstico é feito por ultra-sonografia abdominal, realizada como triagem (em indivíduos assintomáticos, de acordo com o protocolo de cada serviço) ou diante de sintomas específicos. A acurácia do exame varia entre 95 e $98 \%$ e, embora possa não se visualizar cálculos nas vias biliares, o ultra-som identifica a possibilidade dessa condição pela dilatação das mesmas ${ }^{(16)}$. A inocuidade na execução desse exame resultou em aumento no diagnóstico de cálculos assintomáticos $^{(23)}$. Sabe-se que mais da metade dos pacientes pode ser assintomática no momento do diagnóstico da colelitíase $^{(3)}$. Walker $e t a l^{(3)}$ observaram grande porcentagem de pacientes assintomáticos num período de 25 anos de seguimento, sugerindo que a investigação por meio de ultra-som e cirurgia seja efetuada apenas em pacientes sintomáticos, o que representou cerca de $7 \%$ da coorte.

Os sintomas mais típicos são plenitude pós-prandial, dor abdominal em hipocôndrio direito ou epigastro, náuseas, vômitos e intolerância a alimentos com alto teor de gordura. A colecistite aguda pode apresentar, além desses sintomas, febre, alteração do hábito intestinal e piora da icterícia, colúria ou acolia fecal ${ }^{(24)}$. As complicações agudas e crônicas incluem colecistite, dismotilidade da vesícula biliar, colan- 
gite, pancreatite, perfuração da vesícula biliar e migração do cálculo para colédoco e vias biliares.

A dor abdominal inespecífica é um desafio diagnóstico no paciente falciforme. Além de todos os diagnósticos diferenciais de dor abdominal na infância, que incluem parasitoses intestinais, constipação intestinal, doença péptica, pancreatite, apendicite aguda, intolerância/alergia alimentar e intolerância à lactose, o pediatra ainda se depara com a dificuldade dos diagnósticos diferenciais inerentes à doença falciforme. Dentre esses, pode-se destacar o seqüestro hepático, o seqüestro esplênico, a crise vaso-oclusiva abdominal e a colelitíase ${ }^{(8,13)}$

\section{Tratamento da colelitíase}

Existe consenso de que a colecistectomia é o tratamento de escolha para a colelitíase sintomática ${ }^{(7,23,25)}$. A colecistite aguda, sempre que possível, deve ser tratada de maneira conservadora, com antibióticos, hidratação, correção de distúrbios eletrolíticos e medidas gerais para o alívio dos sintomas. A colecistectomia é indicada logo após a fase aguda, a fim de evitar aderências ao redor da vesícula inflamada ${ }^{(7)}$. A cirurgia de urgência está indicada nos casos de obstrução biliar.

As vias cirúrgicas utilizadas são a laparotomia e a laparoscopia, sendo que a maioria dos autores considera a segunda de maior segurança para o paciente falciforme ${ }^{(26-29)}$, com menos complicações relacionadas à cirurgia, menor tempo cirúrgico e recuperação pós-operatória mais rápida.

A história natural dos cálculos biliares assintomáticos não foi estudada. A indicação de colecistectomia eletiva para colelitíase assintomática ainda é controversa ${ }^{(7,8)}$. O manejo de cálculos descobertos acidentalmente constitui-se num dilema, já que os benefícios da colecistectomia são desconhe$\operatorname{cidos}^{(23)}$. Walker et al ${ }^{(3)}$ observou grande número de pacientes assintomáticos num período de 25 anos de seguimento e sugeriu que a investigação e a cirurgia sejam indicados apenas em pacientes sintomáticos. O autor ressalta, porém, que a colecistectomia feita nos portadores de litíase permite excluir esse diagnóstico diferencial em pacientes que apresentam dor abdominal recorrente, o que facilitaria o diagnóstico de crise vaso-oclusiva abdominal, bastante freqüente e com sintomas semelhantes ${ }^{(3)}$.

Os autores divergem quanto à indicação de colecistectomia e à conduta frente ao paciente assintomático. Alguns acreditam que o risco do desenvolvimento de sintomas é baixo, em longos períodos de seguimento, com freqüência reduzida de complicações ${ }^{(16,23,30,31)}$. Tais autores alegam também ser desconhecida a freqüência de migração espontânea de cálculos para o duodeno ${ }^{(30)}$. Há indícios de que algumas populações de pacientes assintomáticos podem ser conduzidas clinicamente por longos períodos, sendo indicados antiespasmódicos e dieta hipogordurosa diante de sintomas vagos ou ocasionais ${ }^{(7,16)}$.

Na década de 1990, alguns estudos sugeriam a conduta expectante no paciente assintomático, tendo como justificativa a possibilidade de a litíase biliar levar longo período de tempo para apresentar sintomas ou nunca fazê-lo. A colecistectomia, mesmo sendo uma cirurgia eletiva, apresenta risco cirúrgico não desprezível, atingindo $1 \%$ de mortalidade, dentre o total de procedimentos ${ }^{(32-34)}$. Para pacientes falciformes com litíase biliar assintomática, sugeria-se acompanhamento clínico atencioso e rotineiro.

Outro argumento contrário à indicação de colecistectomia na ausência de sintomas seria o fato de a cirurgia expor os pacientes portadores da anemia hemolítica a diversos fatores que precipitam a falcização dos eritrócitos, facilitando o desencadeamento de crise hemolítica grave. Mesmo com cuidados pré-operatórios, pacientes falciformes chegam a apresentar $25 \%$ de morbidade ${ }^{(8,35)}$. As maiores complicações pós-operatórias descritas são: atelectasia, pneumonite, infarto pulmonar (crise vaso-oclusiva pulmonar) e infecções ${ }^{(7,36)}$.

A colecistectomia é associada à baixa, porém não desprezível, mortalidade. Certamente, o advento da técnica laparoscópica fez com que houvesse diminuição da morbimortalidade, o que veio a complicar o dilema referente ao manejo da colelitíase assintomática ${ }^{(23)}$. Com o advento e a propagação da cirurgia vídeo-laparoscópica, a controvérsia quanto à indicação cirúrgica dos pacientes assintomáticos manteve-se, porém, em razão de ser a cirurgia minimamente invasiva, as indicações de colecistectomia eletiva nos pacientes assintomáticos sem dúvida aumentaram ${ }^{(37,38)}$.

Holcomb e Holcomb advogam a realização de colecistectomia no paciente falciforme assintomático devido ao risco de complicações potencialmente fatais, pela presença ou migração do cálculo, tais como a coledocolitíase, a obstrução do duto biliar comum, a pancreatite, a perfuração, a peritonite biliar e a sepse ${ }^{(25)}$. Em sua experiência, a morbidade e mortalidade que se seguem à colecistectomia são relativamente baixas na faixa etária pediátrica, em comparação a cirurgias realizadas em situação de urgência ou após o primeiro episódio de colecistite.

As vantagens da colecistectomia eletiva foram descritas por Suell et al ${ }^{(39)}$, que observaram maior segurança na 
Tabela 1 - Condutas sugeridas ao diagnóstico de colelitíase no paciente falciforme, segundo os diversos autores e número de pacientes estudados $(n)$

\begin{tabular}{|c|c|c|}
\hline Autores & $\mathbf{n}$ & Conduta sugerida \\
\hline Curro et $a^{(41,42)}$ & 76 & $\begin{array}{l}\text { Cirurgia eletiva é padrão-ouro para crianças assintomáticas pelo potencial de prevenir } \\
\text { complicações da colelitíase, promover menor desconforto e tempo de hospitalização }\end{array}$ \\
\hline Al Salem et $a /^{(10,43)}$ & 47 & $\begin{array}{l}\text { Realizar colecistectomia no paciente assintomático, pois previne complicações e simplifica manejo } \\
\text { futuro diante de dor abdominal }\end{array}$ \\
\hline Seleem et $a{ }^{(44)}$ & 75 & $\begin{array}{l}\text { Indicar cirurgia eletiva por prevenir dor abdominal recorrente, melhorar a qualidade de vida } \\
\text { e por ser procedimento seguro }\end{array}$ \\
\hline Winter et $a{ }^{(45)}$ & 75 & Recomendar cirurgia eletiva devido ao risco de complicações \\
\hline Walker et $a)^{(3)}$ & 96 & $\begin{array}{l}\text { Investigar com ultra-som apenas os sintomáticos e fazer seguimento clínico nos } \\
\text { assintomáticos, pelo baixo risco de desenvolvimento de sintomas e complicações }\end{array}$ \\
\hline Bond et al(46) & 47 & Colecistectomia deve ser realizada se surgirem sintomas ou complicações \\
\hline Rudolph et al(47) & 14 & Sugere a colecistectomia precoce apenas para pacientes sintomáticos \\
\hline
\end{tabular}

colecistectomia eletiva, com menor tempo de internação pós-operatória no paciente assintomático e retorno mais rápido às suas atividades rotineiras. Nesse estudo, não se observou risco cirúrgico aumentado de complicações relacionadas ao procedimento, quando comparados os grupos eletivo e de urgência. Dado inédito obtido por Suell et $a^{(39)}$, foi o fato de pacientes assintomáticos já possuirem alterações histológicas na vesícula biliar, indicando existir colecistite crônica assintomática.

A dor secundária à colelitíase confunde-se clinica e laboratorialmente com crise hepática ou crise vaso-oclusiva abdominal. Pela dificuldade diagnóstica da crise dolorosa abdominal no paciente falciforme, na presença do cálculo, poderia ser indicada a colecistectomia eletiva assim que é confirmada a presença do cálculo biliar ${ }^{(36)}$. Os protocolos americanos de conduta frente a complicações de colelitíase em falciformes sugerem que cada caso seja avaliado individualmente, havendo base na literatura para optar pela conduta expectante, ou seja, o seguimento clínico ${ }^{(40)}$.

A Tabela 1 sumariza as condutas sugeridas por diversos autores, ao diagnóstico de colelitíase no paciente falciforme.

A hemólise decorrente da anemia falciforme é fator de risco reconhecido para o desenvolvimento de cálculos biliares, os quais são, em geral, múltiplos e pigmenta- dos. A freqüência de colelitíase aumenta com a idade, atingindo mais de $50 \%$ dos adultos falciformes e é maior em pacientes portadores de quadros clínicos com hemólise exacerbada. Os portadores de colelitíase podem ser assintomáticos em até $50 \%$ e o diagnóstico é feito por ultra-sonografia rotineira. Em pacientes sintomáticos, a colecistectomia aberta ou laparoscópica é o tratamento de escolha. A controvérsia permanece sobre o manejo do paciente assintomático. Dependendo de características individuais e da população, pode ser aceito o seguimento clínico ou a indicação precoce de colecistectomia. Alguns autores recomendam o acompanhamento clínico minucioso e regular, com ultra-sonografia rotineira, argumentando que a fase assintomática pode durar anos e que a cirurgia, mesmo laparoscópica, não está isenta de complicações nem tem morbimortalidade desprezível. Após o advento e a evolução da técnica cirúrgica laparoscópica, a maior parte dos autores tende a recomendar a cirurgia eletiva, por acreditar que a cirurgia laparoscópica é segura e que a sua realização elimina o diagnóstico diferencial de colelitíase num episódio futuro de crise dolorosa abdominal. Há indícios de que a cirurgia eletiva precoce leva a um menor tempo de internação hospitalar e recuperação pósoperatória mais rápida. 


\section{Referências bibliográficas}

1. Di Nuzzo DV, Fonseca SF. Anemia falciforme e infecções. J Pediatr (Rio J) 2004;80:347-54.

2. Lane PA, Nuss R, Ambruso DR. Hematologic disorders. In: Hay Jr WW, Hayward AR, Levin MJ, Sondheimer JM, editors. Current pediatric diagnosis \& treatment. $14^{\text {th }}$ ed. London: Prentice-Hall; 1999. p. 739-41.

3. Walker TM, Hambleton IR, Serjeant GR. Gallstones in sickle cell disease: observations from the Jamaica Cohort study. J Pediatr 2000;136:80-5.

4. Billa RF, Biwole MS, Juimo AG, Bejanga BI, Blackett K. Gall stone disease in African patients with sickle cell anaemia: a preliminary report from Yaounde, Cameroon. Gut 1991;32:539-41.

5. Malone BS, Werlin SL. Cholecystectomy and cholelithiasis in sickle cell anemia. Am J Dis Child 1988;142:799-800.

6. Papadaki MG, Kattamis AC, Papadaki IG, Menegas DG, Georgakopoulou TP, Mavrommati-Metaxotou Aet al. Abdominal ultrasonographic findings in patients with sickle cell anaemia and thalassaemia intermedia. Pediatr Radiol 2003;33:515-21.

7. FG Laboratorio [homepage on the Internet]. Manual de Anemia Falciforme [cited 2007 Jun 15]. Available from: http://www.fglaboratorio.com.br/artigo_02.htm

8. Schubert TT. Hepatobiliary system in sickle cell disease. Gastroenterology 1986;90:2013-21.

9. Nzeh DA, Adedoyin MA. Sonographic pattern of gallbladder disease in children with sickle cell anaemia. Pediatr Radiol 1989;19:290-2.

10. Al-Salem AH. Should cholecystectomy be performed concomitantly with splenectomy in children with sickle cell disease? Pediatr Surg Int 2003;19:71-4.

11. Parez N, Quinet B, Batut S, Grimprel E, Larroquet M, Audry G et al. Cholelithiasis in children with sickle cell disease: experience of a French pediatric hospital. Arch Pediatr. 2001;8:1045-9.

12. Costa PJ, Vilela RQ, Cipolotti R, Figueiredo MS. Diversidade clínica e laboratorial no haplótipo bantu da anemia falciforme. Revista Bras Hematol Hemoter 2006;28:40-4.

13. Al-Salem AH, Qaisruddin S. The significance of biliary sludge in children with sickle cell disease. Pediatr Surg Int 1998;13:14-6.

14. Winter SS, Kinney TR, Ware RE. Gallbladder sludge in children with sickle cell disease. J Pediatr 1994;125:747-9.

15. Walker TM, Serjeant GR. Biliary sludge in sickle cell disease. J Pediatr 1996;129: 443-5.

16. Bottura AC, Hessel G, de Tommaso AM. Colelitíase não hemolítica na infância e na adolescência. Rev Paul Pediatr 2007;25:90-7.

17. Ruibal Francisco JL, Aleo Luján E, Álvarez Mingote A, Piñero Martínez E, Gómez Casares R. Colelitiasis en la infancia. Análisis de 24 pacientes y revisión de 123 casos publicados en España. An Esp Pediatr 2001;54:120-5.

18. Monaghan G, Ryan M, Seddon R, Hume R, Burchell B. Genetic variation in bilirubin UDP-glucuronosyltransferase gene promoter and Gilbert's syndrome. Lancet 1996;347:578-81.

19. Passon RG, Howard TA, Zimmerman SA, Schultz WH, Ware RE. Influence of bilirubin uridine diphosphate glucuronosyltransferase $1 \mathrm{~A}$ promoter polymorphisms on serum bilirubin levels and cholelithiasis in children with sickle cell anemia. J Pediatr Hematol Oncol 2001;23:448-51.

20. Heeney MM, Howard TA, Zimmerman SA, Ware RE. UGT1A promoter polymorphisms influence bilirubin response to hydroxyurea therapy in sickle cell anemia. J Lab Clin Med 2003;141:279-82.

21. Fertrin KY, Melo MB, Assis AM, Saad ST, Costa FF. UDP-glucuronosyltransferase 1 gene promoter polymorphisms is associated with increased serum bilirubin levels and cholecystectomy in patients with sickle cell anemia. Clin Genetics. 2003;64:160-2.

22. Chaar V, Kéclard L, Diara JP, Leturdu C, Elion J, Krishnamoorthy R et al. Association of UGT1A1 polymorphism with prevalence and age at onset of cholelithiasis in sickle cell anemia. Haematologica 2005;90:188-99.

23. Meshikhes AW. Asymptomatic gallstones in the laparoscopic era. J R Coll Surg Edinb 2002;47:742-8.

24. Honig GR. Hemoglobin disorders. In: Nelson WE, Behrman RE, Kliegman RM, Arvin AM editors. Nelson textbook of pediatrics. $15^{\text {th }}$ ed. Philadelphia: W.B. Saunders; 1996. p. 1396-400.
25. Holcomb GW Jr, Holcomb GW $3^{\text {rd }}$. Cholelithiasis in infants, children, and adolescents. Pediatr Rev 1990;11:268-74.

26. Leandros E, Kymionis GD, Konstadoulakis MM, Albanopoulos K, Dimitrakakis K, Gomatos I et al. Laparoscopic or open cholecystectomy in patients with sickle cell disease: which approach is superior? Eur J Surg 2000;166:859-61.

27. Al-Salem AH, Nourallah H. Sequential endoscopic/laparoscopic management of cholelithiasis and choledocholithiasis in children who have sickle cell disease. J Pediatr Surg 1997;32:1432-5.

28. Tagge EP, Othersen HB Jr, Jackson SM, Smith CD, Gayoso AJ, Abboud MR et al. Impact of laparoscopic cholecystectomy on the management of cholelithiasis in children with sickle cell disease. J Pediatr Surg 1994;29:209-12.

29. Meshikhes AN, al-Dhurais SA, al-Jama A, al-Faraj AA, al-Khatir NS, al-Abkar $\mathrm{H}$. Laparoscopic cholecystectomy in patients with sickle cell disease. J R Coll Surg Edinb 1995;40:383-5.

30. Roberts-Thomson IC. The management of bile duct stones. Indian J Gastroenterol 2004;23:102-6.

31. Serjeant GR, Serjeant BE. Management of sickle cell disease; lessons from the Jamaican Cohort Study. Blood Rev 1993;7:137-45.

32. Fendrick AM, Gleeson SP, Cabana MD, Schwartz JS. Asymptomatic gallstones revisited. Is there a role for laparoscopic cholecystectomy? Arch Fam Med 1993;2:959-68

33. Ransohoff DF, Gracie WA. Treatment of gallstones. Ann Intern Med. 1993;119:606-19.

34. Duncan ND, McDonald AH, Mitchell DI. Cholecystectomy in Jamaican children with homozygous sickle-cell disease. Trop Doct. 2000;30:214-6.

35. Buck J, Davies SC. Surgery in sickle cell disease. Hematol Oncol Clin North Am 2005;19:897-902.

36. Hemonline [homepage on the Internet]. Condutas no paciente com anemia falciforme [cited 2007 Jun 15]. Available from: http://www.hemonline.com. br/a falc.htm

37. Séguier-Lipszyc E, de Lagausie P, Benkerrou M, Di Napoli S, Aigrain Y. Elective laparoscopic cholecystectomy. Surg Endosc 2001;15:301-4.

38. Hendricks-Ferguson V, Nelson MA. Treatment of cholelithiasis in children with sickle cell disease. AORN J 2003;77:1170-8.

39. Suell MN, Horton TM, Dishop MK, Mahoney DH, Olutoye OO, Mueller BU. Outcomes for children with gallbladder abnormalities and sickle cell disease. J Pediatr 2004;145:617-21.

40. National Institutes of Health [homepage on the Internet]. The management of sickle cell disease [cited 2007 Jun 15]. Available from: http://www.nhlbi.nih. gov/health/prof/blood/sickle/index.htm

41. Currò G, lapichino G, Lorenzini C, Palmeri R, Cucinotta E. Laparoscopic cholecystectomy in children with chronic hemolytic anemia. Is the outcome related to the timing of the procedure? Surg Endosc 2006;20:252-5.

42. Curro G, Meo A, Ippolito D, Pusiol A, Ciconotta E. Asymptomatic cholelithiasis in children with sickle cell disease: early or delayed cholecystectomy? Ann Surg 2007;245:126-9

43. Al-Salem AH. Indications and complications of splenectomy for children with sickle cell disease. J Pediatr Surg 2006;41:1909-15.

44. Seleem MI, Al-Hashemy AM, Meshref SS. Mini-laparoscopic cholecystectomy in children under 10 years of age with sickle cell disease. ANZ J Surg 2005;75:562-5.

45. Hatley RM, Crist D, Howell CG, Herline AJ, Gadacz TR. Laparoscopic cholecystectomy in children with sickle cell disease. Am Surg 1995;61:169-71.

46. Bond LR, Hatty SR, Horn ME, Dick M, Meire HB, Bellingham AJ. Gall stones in sickle cell disease in the United Kingdom. Br Med J (Clin Res Ed) 1987;295:234-6.

47. Rudolph R, Williams JS. Cholecystectomy in patients with sickle cell disease: experience at a regional hospital in southeast Georgia. J Natl Med Assoc 1992;84:692-6. 